\title{
Pemikiran Hadis di Indonesia (Studi Analisis Terhadap Nahdlatul Ulama)
}

\author{
Wely Dozan, M. Dani Habibi \\ Universitas Islam Negeri Sunan Kalijaga Yogyakarta \\ e-mail: welydozan77@gmail.com
}

\begin{abstract}
This article examines NU (Nahdlatul Ulama) which is an organizational structure among Muslims who have trends in applying Islamic law. One of the foundations of the Nahdatulllama in establishing Islamic law has never been separated from the context of the Qur'an, Hadith, Ijma 'of the Companions and Qiyas. So the outline in taking the source of Islamic law is related to the hadith problem which is made as a reference in the sense of $\mathrm{Nu}$ in using hadith as the legal basis for four schools, moreover the usual lower hadith, dha' if hadith is used as a source search method law. Taking in the community often discussed the system of extracting Islamic legal sources. We will analyze this short article by analyzing the methods that are used at the same time in order to find out the hadiths used in applying the source of Islamic. The results of this study show that the hadith in the perspective of NU scholars is as a reference to Islamic law and that the hadith has a strong blasphemy based on the study of sanad, matan, and rawi as well as the quality and quantity of hadith based on methods in attributing Islamic law.
\end{abstract}

Keywords: Nahdlatul Ulama, Hadith, Method.

\begin{abstract}
Abstrak
Artikel ini mengkaji NU (Nahdlatul Ulama) yang merupkan suatu struktur organisasi yang berpengaruh di kalangan umat muslim yang memiliki trend-trend dalam mengistinbatkan hukum Islam. Salah satu yang menjadi landasan-landasan Nahdlatul Ulama dalam mengistinbatkan hukum Islam tidak pernah terlepas dari konteks Al-Qur'an, Hadits, Ijma' para sahabat dan Qiyas. Adapun yang menjadi garis besar dalam pengambilan sumber hukum Islam terkait masalah hadits yang dijadikan sebagai rujukan dalam arti Nu dalam menggunakan hadist sebagai dasar hukum merujuk kepada empat mazhab lebih-lebih hadits yang biasa terendah adalah hadits dha'if diterapkan sebagai metode pengambilan sumber hukum. Sehingga dikalangan masyarakat sering diperbincangkan sistem pengambilan sumber hukum Islam. Tulisan yang singkat ini akan kita analisi metode-metode yang dipakai sekaligus guna untuk mengetahui hadits-hadits yang dipakai dalam mengistinbatkan sumber hukum Islam tersebut. Hasil penelitian ini bahwa hadits dalam perspektif ulama NU adalah sebagai istinbat hukum Islam dan tentu hadits tersebut memiliki kehujjahan yang kuat berdasarkan kajian sanad, matan, dan rawi serta kualitas dan kuantitas hadits yang didasarkan pada metodemetode dalam mengistinbatkan hukum Islam.
\end{abstract}

Kata Kunci: Nahdlatul Ulama, Hadis, Metode.

\section{Pendahuluan}

Kehadiran NU merupakan salah satu upaya untuk melembagakan wawasan tradisi keagamaan yang dianut jauh sebelumnya, yakni paham Ahlussunnah wal Jama'ah yang memiliki teks-teks dan doktrin yang perlu dikaji 
dalam konteks baris besarnya adalah hadits sebagai sumber istinbath dalam hukum Islam ${ }^{1}$

Membincangkan dan mengkaji teks-teks agama dalam konteks suatu budaya menjadi sesuatu hal yang sangat menarik. Sebab didalamnya terdapat suatu gambaran bagaimana sebuah teks itu berintraksi dengan konteks sisiologis, geografis, tentu semua ini memiliki banyak hal perbedaan, sehingga dalam konteks mengistinbatkan sumber hukum Islam dapat dipahami dan dimaknai berbeda oleh orang ataupun sekelompok yang tinggal di Arab maupun yang tinggal diluar Arab, misalnya Indonesia yang memiliki salah satu struktur organisasi keagamaan di Indonesia adalah Nahdlatul Ulama yang biasanya di sebut NU yang memiliki tradisi ilmiah bahtsul masail.

Dalam kegiatan bahtsul masail tersebut tidak menutup kemungkinan jika Nahdlatul Ulama telah berintraksi dengan teks-teks keagamaan, didalamnya termasuk teks berupa Al-Qur'an maupun hadist sebagai kajianya. Kajian tersebut sangat menarik untuk diketahui, karena berangkat dari pemakanaan dan pemahamn teks hadits Nabi Muhammad Saw adalah sebuah problematika yang

${ }^{1}$ Tim Aswaja NU Center PWNU Jawa Timur, Khazanah Aswaja, "Memahamai, Mengamalkan dan Mendakwahkan Ahlussunah wal Jama'ah" (JawaTimur: Tim Aswaja NU Center PWNU, 2016), hlm.407 menjadi perbedaan dalam memberikan penjelasan yang perlu dikaji secara ilmiah.

Sebagai organisasi keagamaan, Nahdlatul Ulama tetap memilki keunikan untuk dikaji, diamati, diteliti dan dibaca dari berbagai optik dan pemikiran, lebihlebih dalam masalahpemahaman terhadap sumber hukum pertama dan yang utama Islam seperti, al-Qur'an dan al-hadits. Menarik untuk dilihat kembali, berangkat dari keunikan NU yang dalam memahami dan sekaligus pengambilan hukum (istinbat al-hukm) seakan-akan tidak didasarkan pada ke orisinalan pemahaman mereka terhadap kedua sumber tersebut.

Maka dari itu itu muncul banyak pernyataan maupun kritikan bahwa organisasi yang konon terbesar di Indonesia ini dalam mengambil keputusan dan menjawab persoalan umat tidak bersumber dari al-Qur'an dan Hadis minimal tidak langsung bersumber dari al-Qur'an dan hadis sehingga memicu pertentangan diantara sesama umat menyangkut amaliyah NU. Oleh karena itu NU perlu dikaji lebih jauh lagi untuk mengetahui proses-proses dalam mengistinbatkan suatu hukum Islam dengan menggunakan berbagai macam aspek untuk perlu diketahui sebagai alasan dasar pengambilan hukum tersebut. 


\section{Pemikiran NU dalam Bidang Keagaman}

Nahdlatul Ulama Sebagai salah

satu dari jam'iyyah keagamaan dan organisasi kemasyarakatan, bertujuan membangun dan mengembangkan insan dan masyarakat yang bertaqawa kepada Allah senantiasa berpegang teguh pada kaedah-kaedah keagamaan Islam dan kedah-kaedah kenegaraan dalam merumuskan pendapat melalui al-Qur'an dan hadits. Adapun pemikiran NU dalam bidang keagamaan secara ringkas dapat dibagi dalam tiga bidang yakni bidang aqidah, fiqhi dan tasawuf, adapaun penjelasan ringkasnya sebagai berikut:

a. Di bidang aqidah, NU menganut paham ahlussunnah wal jama'ah yang dipelopori oleh oleh Imam Abu Hasan al-Asy'ari² (260-324 H), dan Imam Abu Mansyur alMaturidi $^{3}$ (w. 333 H/944 M). ${ }^{4}$

${ }^{2}$ Asy'arisme adalah nama sebuah aliran pemikiran filsafat keagamaan yang berkembang pada abad ke-4 dan ke-5/ke-10 dan ke-11. Pergerakan ini merupakan suatu upaya yang bukan saja dimaksudkan untuk membersihkan Islam dari segala unsur non Islam yang secara diam-diam telah masuk ke dalam Islam, tetapi juga untuk mengharmonisasikan kesadaran keagamaan dengan pemikiran keagamaan dalam Islam. Asy'arisme meletakkan fondasi sebuah teologi Islam ortodoks atau kalam ortodoks sebagai lawan dari kalam rasionalis dari kaum Mu'tazilah yang menentang aliran (mazhab) ortodoks ekstrim, Asy'arisme menggunakan metode dialektika demi untuk mempertahankan otoritas wahyu Ilahi sebagaimana diterapkan pada masalah-masalah teologis. Baca selengkapnya, Sharif, Aliran-Aliran Filsafat Islam, hlm..51

3Dalam kitab Al-Tauhid, al maturudi menyajikan pembahasan luas dan mendalam mengenai sistem pemikiranya dan berusaha untuk mengharmonisasikan paham-paham ekstrim dari kaum tradisional dan kaum rasional. Kitab ini membuktikan bahwa dia memiliki pengetahuan yang luas dan b. Di bidang fiqih, NU mengikuti jalan pendekatan salah satu dari empat mazhab, keempat mazhab tersebut adalah Abu Hanifah An Num'an (80-150 H/ 700-767 M), imam Malik bin Anas (93-179 $\mathrm{H} / 713-795 \quad \mathrm{M}), \quad$ Imam Muhammad bin Idris Al-Syafi'I $(150-204 \quad \mathrm{H} / 767-820 \quad \mathrm{M})$ serta Imam Ahmad bin Hanbal (164$241 \mathrm{H} / 780-855 \mathrm{M})$.

c. Di bidang tasawuf, NU mengikuti tasawuf Imam Al-Junaidi AlBaghdadi (w.297 H), dan Imam Abu Hamid al-Ghazali (450-505 H). ${ }^{5}$

Adapun paham keagamaan yang menjadi landasan NU tersimpul dalam sebuah kaidah ${ }^{6}$

$$
\text { الما فظة علي القديم الصالح والأخذ بالجديد الأصلح }
$$

Artinya: Memelihara nilai-nilai terdahulu yang sudah baik, dan

mendalam di bidang filsafat pada masanya. Dalam karangan ini akan kami buktikan juga bahwa al-maturidi merupakan mutakallim pertama yang memperkenalkan doktrin mengenai sumber-sumber pengetahuan manusia dalam sebuah buku teologi seperti kitab al-Tauhid. Lihat juga di Sharif, Aliran-Aliran Filsafat Islam, hl..101

${ }^{4}$ Ahmad Zahro, TradisiIntelektual NU Lajnah Bahtsul Mas'ail 1926-1999, (yogyakarta: LKIS Yogyakarta 2004), hlm. 19

${ }^{5}$ Abdul Muchit Muzadi, Mengenal Nahdkatul Ulama, (Surabaya: Khalista. 2004) Cet; IV, h. 25-26

${ }^{6}$ Kaidah (ditulis dalam tanda kutip statusnya sebagai kaidah dianggap belum baku, terbukti masih adanya penyebutan lain, seperti slogan, jargon, kata hikmah etos dan sebagainya) sedang di Indonesia antara lain dipopulerkan oleh Ahmad Siddiq dan Nurcholis Madjid yang kemudian diterima sebagai kaidah keberagamaan bagi NU. Liha tUlil Abshar Abdalla, "NU dan Generasi Baru" Dalam Dinamika Kaum Muda" ,(jakarta: PP-IPNU, 1997), hlm. 100. 
mengambil nilai-nilai baru yang lebih baik. Kaidah ini sebenarnya bukan klaim tunggal NU, dan NU juga tidak pernah mengklaim sebagai satu-satunya kaidah miliknya, yang hanya saja populer dikalangan warga NU.7Landasan pijak kaidah diatas adalah masih bersifat universal, dalam arti banyak hal peristiwa maupun ajaran yang orientasinya "memelihara yang sudah baik dan mengambil yang lebih baik." Ajaran Islam sendiri juga pada hakikatnya demikian. Nilai-nilai masa lalu yang baik dipertahankan dengan memperkenalkan syari'at (ajaran) baru yang lebih baik, bahkan sekitar dua pertiga al-Qur'an menceritakan umat masa lalu agar umat masa kini dapat memetik hikmah dan pelajaran darinya. ${ }^{8}$

Nurcholis Madjid kemudian menjelaskan bahwa, dalam konteks keindonesiaan seharusnya "kaidah" teresebut seharusnya milik semua organisasi kemasyarakatan Islam, baik yang tradisionalis maupun modernis, baik NU, NW, Persis, Muhammadiyah, al-

${ }^{7}$ Ahmad Zahro, Tradisi Intelektual NU Lajnah Bahtsul Mas'ail 1926-1999, h. 21

${ }^{8}$ Mengenai ayat- al-Qur'an memang sebagiannya banyak yang mebicarakan kembali masa umat terdahulu, sepertikisah-kisahnabi Yunus dan umatnya, kisah nabi Musa dan Umatnya, kisah Fir'aun dan lain sebagainya, kisah-kisah ini dapat dilacak dari berbagai surat seperti alAnbiya', QS Yunus, QS Yusuf, QS Al-Qashash dal lain sebagainya.
Irsyad ataupun lainnya. ${ }^{9}$ tanpa perlu ada yang diperselisihkan. Yang perlu justru saling memahami karena masing-masing merasa ikut memilki kaidah tersebut, namun jika harus berbagi, biarlah yang tradisionalis mengurus "memelihara nilainilai terdahulu yang sudah baik", sedang yang modernis agar tetap memperhatikan "mengambil nilai-nilai baru yang lebih baik", namun tetap dalam kesatuan "kaidah" dalam arti berbagi tugas tanpa perlu terjadi pembelahan yang menjurus kepada perpecahan.

Bertolak dari kaidah diatas NU dengan gigih berusaha mempertahankan nilai-nilai terdahulu yang di yakini baik yang dibidang fiqh terwujud dalam kesetiaan Lajnah Bahtsul Masa'il pada naskah kitab-kitab kuning sebagai andalan utama guna menghadapi berbagai masalah keagamaan yang diajukan masyarakat Nahdliyin sekalipun persoalan tersebut dapat dikategorikan sebagai maslah fiqh kontemporer seperti transplantasi organ tubuh, cloning gen, demonstrasi dan sebagainya.

Bentuk lain dari kekokohan NU dalam mempertahankan nilai-nilai terdahulu yang diyakini baik adalah sikap toleran dan kooperatifnya terhadap tradisi keberagmaan yang telah berkembang

9 Ahmad Zahro, Tradisi Intelektual NU Lajnah Bahtsul Mas'ail 1926-1999, h. 22 
dimasyarakat, seperti membaca al-barzanji dan diba' (sejarah dan pujian terhadap bagi Nabi SAW), wiridan kolektif seusai shalat berjamaah, puji-pujian antara adzan dan iqamat, tahlilan (membaca kalimat "thayyibah" la ilaha illallah dirangkai dengan bacaan-bacaan tertentu), yasinan (membaca surat Yasin dalam waktuwaktu tertentu), yang menurut kaum modernis tidak perlu lagi dilestarikan, bahkan sebagian menganggapnya sebagai bid'ah yang harus diberantas.

Dalam wacana keagamaan muncul dua aliran keagamaan yang dalam hal-hal tertentu bertentangan secara dimetral, kedua aliran tersebut adalah modernis dan kaum tradisionalis. Mereka mempersoalkan mazhab dan ijtihad Ahlu Sunnah wa al-Jamaah yang oleh kaum modernis dituduh sebagai bid'ah dan Khurafat yang mendekati syirik. Modernis menyerang kitab-kitab klasik yang dijadikan kaum tradisionalis sebagai sumber rujukan dalam pengambilan hukum, modernis menyerukan untuk kembali kepada al-Qur'an al-Hadis, sebaliknya kaum tradisionalis beranggapan bahwa kitab-kitab itu masih tetap relevan untuk memahami hukum islam dari sumber aslinya.

Gerakan ini oleh Tradisionalis (baca; kalangan NU) dianggap sebagai ancaman, sebaliknya taqlid dan lainnya dipandang sebagai penyimpangan dari alQur'an dan hadis oleh kalangan modernis. Mengenai taqlid, K.H.M Hasyim Asy'ari sebagai orang "tertua" dari kalangan tradisi menulis panjang lebar apa yang dimaksudkan dan arti penting taqlid bagi orang yang tidak berpengetahuan:

Menurut mayoritas Ulama yang sudah mendalam ilmunya, setiap orang yang tidak mempunyai kemampuan ijtihad wajib mengikuti pendapat ulama' mujtahid dan fatwa-fatwa mereka walaupun islam telah memperoleh sebagian ilmu yang masuk dalam kualifikasi ijtihad. Hal ini agar Ia keluar dari beban taqlid kepada salah satu yang dikehendakinya. Allah berfirman, "Maka bertanyalah kepada orang-orang yang berpengatahuan jika kamu tidak mengetahui" Allah mewajibkan bertanya bagi orang yang tidak berpengetahuan, dan itu artinya orang harus taqlid kepada orang yang berpengetahuan mencakup seluruh manusia agar mereka bertanya masalah apapun yang tidak mereka ketahui ${ }^{10}$

\section{Mazhab Sebagai Metode (Manhaj) dalam ljtihad Nahdlatul Ulama}

Bahtsul Masa'il merupakan forum yang mengkaji masalah-masalah hukum

${ }^{10}$ Hasyim Asy'ari, Sang Kiyai Fatwa, K.H.M Hasyim Asy'ari Seputar Islam dan Masyarakat, Terj: Jamal Ma'rufAsmani, hlm. 187 
agama di lingkungan Nahdlatul Ulama. Forum ini merupakan musyawah untuk mengambil keputusan dan hukum suatu masalah yang dijadikan pegangan bagi warga NU di semua tingkatan. Forum ini bisa disebut ijma' ulama NU sekaligus menunjukkan sekaligus karakterisik NU dalam mengambil keputusan, yaitu melalui konsensus (kesepakatan). ${ }^{11}$

Adapun yang dimaksud dengan pemikiran hukum adalah pandanganpandangan dan dasar-dasar yang secara umum mempengaruhi dan mewarnai pemikiran ulama NU dalam mencandrai suatu permasalahan hukum, sehingga tercetus suatu ketentuan hukum untuk disepakati bersama.Bagi kaum nahdliyyin, suatu masalah yang hendak diputuskan tidak dicarikan norma hukumnya langsung dari al-Qur'an dan hadits

Namun dengan mencari dahulu beberapa pendapat para ulama termasyhur dari abad pertengahan yang terkodifikasi dalam kitab kuning. Istinbdth langsung dari sumber primer yang cenderung pada pengertian ijtihad mutlak, bagi ulama NU dipandang masih sulit dilakukan. Kecenderungan untuk selalu mengaitkan ketetapan hukumnya dengan ketetapan hukum ulama masa lalu yang terekam dalam kitab-kitabnya tidak

${ }^{11}$ Lihat selengkapnya Martin van Bruinessen, Kitab Kuning, Pesantren dan Terkait: Tradisi-Tradisi Islam di Indonesia, (Bandung: Mizan,1999), hlm.17 terlepas dari adanya pandangan bahwa mata rantai ilmu keislaman tidak boleh terputus dari satu generasi kegenerasi berikutnya. ${ }^{12}$

Muchith Muzadi menegaskan bahwa dengan sistem bermazhab baru ajaran Islam yang meliputi kandungan alQur'an dapat dikembangkan, disebar luaskan dan diwariskan kepada segala lapisan atau tingkatan umat Islam. Dengan sistem ini pula pewarisan ajaran Islam terpelihara kelurusan dan kemurniannya, karena ajaran yang terkandung di dalam al-Qur'an dan asSunnah dipahami, ditafsir dan dikembangkan dengan menggunakan pola pemahaman dan metode ijtihad yang dapat dipertanggungjawabkan kebenarannya

Istilah kembali kepada nash tentu tidak boleh diartikan dengan memahami al-Qur'an dan as-Sunnah secara 'bebas' tanpa adanya pola, metode dan prosedur. Adapun sikap ulama NU dalam penggalian dan penetapan hukum dengan sistem bermazhab ini, ditindak lanjuti dengan rumusan bermazhab secara qauli dan manhqi. Bermazhab secara qauli berarti mengikuti mazhab sebagai aqwti (ucapanucapan atau pendapat-pendapat) hasil

${ }^{12}$ Sukron Ma'mun, Ilhaq dalam Bahtsul Masa'il Nu: Antara Ijtihad Dan Ikhtiyat, (Jurnal: Vol. 28 No. 1 januari 1 April, 2011), hlm.67 
pemikiran atau istinbdth dengan menggunakan suatu manhq. Rumusan ini diimplementasikan dalam metode penetapan hukum dengan memakai 'ibtirah yang ditemukan dalam teks kitab kuning. Bermazhab secara manhq;i dimaksudkan dengan mengikuti mazhab sebagai metode berfikir dalam menggali hukum Islam dari al-Qur'an dan asSunnah untuk menemukan pendapat hukum.

Bermazhab secara manhaji dilakukan dengan cara istinbath jama'i, yaitu upaya mendapatkan kesimpulan pendapat atauhukum secara kolektif. Dengan demikian dimaksudkan hasilnya akanlebih akurat. Bermazhab secara manhaji yang dilakukan dengan istinbath Jama'i itu diterapkan terhadap hal-hal yang tidak ditemukan (pendapat) di dalam empat mazhab. Artinya, bermazhab qauli didahulukan daripada bermazhab manhaji. Bermazhab secara qauli maupun manhaji tentunya tetap berada dalam kerangka empat mazhab yang telah disepakati, yakni Abu Hanffah, Malik bin Anas, asy-Syafi'I, dan Ahmad bin Hanbal, meskipun sebenamya ada mazhab lain sepertimazhab Imamiyyah dan Zaidiyyah, tetapi keduanya dipandang sebagaiahli bid'ah sehingga pendapatnya tidak boleh diikuti. ${ }^{13}$

\section{Kedudukan Hadis dalam Istinbath Hukum Nahdlatul Ulama'}

NU dalam mengambil sumber ajaran islam menempatkan al-Qur'an sebagai sumber pedoman yang utama kemudian al-Sunnah sebagai sumber hukum islam yang kedua. Nahdlatul Ulama berkeyakinan teguh tidak akan berubah sedikitpun bahwa Islam sebagai agama Allah Swt yang bersumber kepada wahyunya yang telah berwujud kitab alQur'an dan al-Hadis sebagai sumber hakiki. Dalam al-Qur'an dan hadis, sumber hukum sebagai sumber utama hukum Islam bagi NU tidak ada pilihan lain kecuali menerima dan mengikuti hukum yang sudah jelas dan pasti tersebut.

Namun, NU dalam memutuskan dan menyelesaikan persolan (istinbat hukum) terkesan mengabaikan al-Qur'an dan hadis tersebut, sumber hukum islam yang pertama dan utama, hal ini disebabkan NU lebih mengutamakan kehati-hatian (ikhtiyat) dalam memutuskan persoalan hukum sehingga perlunya untuk berkompromi dan 'berkonsultasi' dengan kitab-kitab kuning

13Sukron Ma'mun, Ilhaq dalam Bahtsul Masa'il Nu: Antara Ijtihad Dan Ikhtiyat, (Jurnal: Vol. 28 No. 1 januari 1 April, 2011), hlm . 69-70 
(kitab al-Mu'tabarah) ${ }^{14}$ yang telah ditulis oleh para mujtahid dahulu, lebih dari itu dengan merujuk ke kitab-kitab kuning kembali akan menghindari dari penafsiran eksklusif-fundamentalis terhadap pemahaman al-Qur'an dan al-Hadis karena para perumusnya lebih jauh telah merumuskan "metode" memahami alQur'an dan al-Hadis dan merekalah yang berhak untuk merumuskan jawaban dari permasalahan keagamaan atau yang disebut mujtahid. ${ }^{15}$

${ }_{14}$ Menurut Husein Muhammad Istilah kutub al$m u^{\prime}$ tabarah sangat populer dalam pesantren dan forum Bahtsul Mas'il NU, walaupun istilah itu tidak pernah diketahui dengan pasti muncul dalam khazanah keilmuan Islam. Ada kemungkinan kuat bahwa istilah tersebut lahir bersamaan dengan dekrit penutupan ijtihad yang dikeluarkan pemerintahan Mustain Billah pada masa Abbasiyah. Selanjutnya dalam tulisannya Husein mengkritisi keberadaan kitab tersebut, karena menurutnya sejak awal pembatasan kitab itu telah membuntukan pemikiran keislaman termasuk dalam NU sendiri. Masyhuri dalam mendefinisikan kutub al-mu'tabarah dengan kitab tentang ajaran-ajaran islam yang sesuaidenganakidah Ahlussnunnah wal jama'aah, Masyhuri, Masalah Keagamaan HasilMu'tamar NU, (Surabaya: Dinamika Press.1977), h. 364. Akan tetapi berbedadengan Ahmad Zahro dalam penelitiannyamenguraikan bahwa al$M u^{\prime}$ tabarah yang dimaksud adalah al-kutub 'ala madzahib alarba'ah (kitab yang mengacu pada mazhab empat). Titik Triwulan dan Jonaedi Efendi, Membaca Peta Politik Nahdlatul Ulama' Sketsa Politik Kiyai \& Perlawanan Kaum Muda NU, (Cet; I, Jakarta: Lintas Pustaka.2008), h. 31

${ }^{15}$ Dalam dunia NU, yang tertinggi tingkatnya diantara para mujtahid itu adalah tokoh mujtahid yang mampu berijtihad dengan menggunakan metode dan prosedur yang diciptakan (dirumuskan) sendiri, mujtahid setingkat ini lazimnya disebut dengan mujtahid Muthlaq Mustaqil. Kemudian, dalam memberikan 'gelar' mujtahid di atas, para Ulama salaf sepakat palig tidak ada sebelas syarat-sayarat disebut mujtahid diatas; pertama; menguasai al-Qur'an, kedua; menguasai hadis al-Shahih, ketiga, menguasai bahasa Arab, keempat; menguasai Ilmu Ushul al-Fiqh serta kaidah-kaidahnya, kelima; memahami tujuan pokok syari'at Islam (maqasyid al-Syari'ah), keenam; bertakwa kepada Allah, ketujuh: mustaqil, kedelapan: muntasib, kesembilan: muqayyad, kesepuluh; mujtahid fatwa dan terakhir: mampu mengeluarkan pendapat Imamimam dalam mazhab setelah dipelajari secara mendalam. Abdul Muchith Muzadi, Mengenal Nahdlatul Ulama', (Cet; IV, Surabaya: Khalista, 2006), h. 23-24,
Kemudian, dalam memahami Islam, NU terkesan sangat berhati-hati dan tidak mau memecahkan persoalan keagamaan yang dihadapi dengan merujuk langsung kepada nash al-Qur'an maupun al-Hadis, hal ini juga tidak terlepas dari pandangan bahwa matarantai perpindahan Imu agama Islam tidak boleh terputus dari satu generasi ke generasi berikutnya, yang dapat dilakukan adalah menulusuri mata rantai yang baik dan sah pada setiap generasi. ${ }^{16}$

NU dalam memecahkan persoalan keagamaan yang dihadapi merasa perlu berkonsultasi dengan kitab-kitab yang dianggap mu'tabarah (diakui) yag ditulis ulama' mazhab empat. Demikian juga yang dilakukan terhadap sebagian besar persoalan keagamaan yang dibahas dan ditetapkan keputusan oleh Lajnah Bahtsul Masa'il dari kali pertama (1926) sampai saat ini. Tradisi ini dilestarikan melalui lembaga pendidikan pesantren yang berada dibawah naungan NU. Oleh karena itu sikap dan pandangan yang demikian dalam memahami dan menafsirkan ajaran Islam para pengamat sering menyebut dan mengelompokkan NU dalam golongan Islam tradisionalis. ${ }^{17}$

16Zamakhsyari Dhofier, Tradisi Pesantren, Studi Tentang Pandangan Hidup Kiyai, (Jakarta: LP3ES. 1984), h. 149-153

17Martin Bruinessen, NU Tradisi, Relasi-relasi Kuasa Pencarian Wacana Baru,(Cet; I, Yogyakarta: LKIS. 1994), h. 213 
Ini bukan berarti bahwa NU tidak menghendaki ijtihad, tetapi yang dikehendaki hanyalah ijtihad yang dilakukan oleh orang-orang yang memenuhi persyaratan sebagai mujtahid. Sedangkan bagi yang belum memenuhi persyaratannya dianjurkan lebih baik taqlid$^{18}$ kepada yang telah memenuhi syarat.

Faham taqlid bermazhab menurut Dr.Said Agil Husein al-Munawwar sangat erat kaitannya dengan tradisi intelektual pesantren, transmisi keilmuan yang berlangsung melalui kitab kunig, kitab fiqih yang dipelajari mewarisi fatwa ulama terdahulu dengan sanad yang tak terputus, transmisi seperti ini diyakini memberikan jaminan untuk memperoleh kemurnian ajaran dari sumbernya yang pertama. Oleh karena itu pintu ijtihad menurut NU, hanya terbuka dalam kerangka pemikiran mazhab. ${ }^{19}$ Jadi dalam menyelesaikan masalah Lajnah Bahtsul Masa'il tidak memakai istilah 'ijtihad' melainkan 'istinbath' (penggalian dan penetapan) hukum dengan pendekatan mazhab.

Dr. Ahmad Zahro 'menemukan' bahwa dalam mengaplikasikan pendekatan mazhab, Lajnah Bahtsul

${ }^{18}$ Taqlid baagi NU tidak dipahami sebatas mengikuti tanpa mengetahui dalil melainkan juga mengikuti jalan pemikiran Imam mazhab.

${ }^{19}$ Ahmad Zahro, Tradisi Intelektual NU Lajnah Bahtsul Mas'ail 1926-1999, h.117
Masa'il menggunakan tiga metode istinbat hukum yang diterapkan secara berjenjang, secara ringkas nya adalah:

\section{Metode Qauliy}

Metode ini adalah suatu cara istinbat hukum yang digunakan oleh ulama NU dalam kerja bahthal-masail dengan mempelajari masalah yang dihadapi kemudisn mencari jawabanya pada kitab-kitab figh dari mazhab empat dengan mengacu dan merujuk langsung pada teksnya. Dalam realitanya, menurut warga NU dan para ulama bahwa metode bahtsul Masa'il dengan mengacu pada kitab Imam empat mazhab dengan metode qauliy ini masih refresentatif untuk menjawab segala kebutuhan masyarakat dalam segala zaman berikut tantangannya. ${ }^{20}$

Adapun contoh penggunaan metode qauliy adalah keputusan muktamar NU di surabaya tanggal 13 Rabi' al tahani 1345 H/ 21 Oktober $1926 \mathrm{M}$ tentang orang fasik menjadi wali nikah ${ }^{21}$. Dalam suatu kasus, misalnya: Bolehkah seorang yang tidak mengerjakan ibadah shalat menjadi wali nikah anak perempuanya. NU, Hlm.118

${ }^{20}$ Masyhuri, Masalah Keagamaan Tradisi Intlektual

${ }^{21}$ Imam Ghazali Said, Edisi Revisi Solusi Hukum Islam, Keputusan Muktamar, Munas, dan Konbes Nahdatul Ulama (1926-2004), (Surabaya: Diantama,2006), hlm.9. 
Apabila tidak boleh, maka siapakah yang berhak menjadi wali pada perkawinan itu. Hakim atau lainya?. Seorang fasik karena tidak mengerjakan shalat fardlu atau karena lainya, menurut mazhab, tidak sah menjadi wali nikah anak perempuanya. Tapi menurut pendapat kedua (al-qawl al-thani) sah menjadi wali nikah. Sebagaimana dalam kitab al-Qulyubi al-Mahalli Juz III yang berbunyi:

$$
\begin{aligned}
& \text { لاولاية لفا سق علي المذ هب قال الخلي والقول الثا ني انه } \\
& \text { يلي لأن الفسقت لم يمنعوا من التز ويج في عصر اللأولينز (القليو } \\
& \text { بي علي الخلي في باب ولا ية النكاح الجزء الثالثز }
\end{aligned}
$$

“Menurut mazhab (Syafi'i, yang pertama) orang fasik tidak boleh menjadi wali. Sedangkan menurut al-Mahalli, pendapat kedua, bahwa orang fasik boleh menjadi wali, karena orang-orang fasiq pada masa awal Islam tidak dilarang untuk mengawinkanya

\section{Metode Ilhaqy}

Ilhaqy yang dimaksudkan adalah menyamakan hukum suatu kasus yang jawabannya tidak terdapat dalam kitab al-mu'tabarah dengan hukmun atau masalah serupa yang telah dijawab dalam kitab al-mu'tabarah. metode ini secara operasional sebagaimana qauly juga telah lama diperaktekkan ulama NU untuk menjawab permasalahan yang diajukan masyarakat Nahdliyyin. Metode ini secara opersional sebagaimana qauly juga telah lama diperaktekkan oleh ulama yang meskipun secara implisit belum dinamakan ilhaqy.

Dalam perakteknya ilhaqy menggunakan prosedur dan persyaratan mirip qiyas, karenanya juga dinamakan qiyas versi NU, namun ada perbedaan dari kedua term ini, qiyas memperbandingkan dengan al-Qur'an dan as-sunnah sedangkan ilhaqy memperbandingkan dengan kitab al-mu'tabarah.

\section{Metode Manhajiy}

Yang dimaksudkan dengan metode manhajiy adalah bermazhab dengan mengikuti jalan pikiran dan kaidah penetapan hukum yang telah disusun oleh Imam mazhab. Sebagaimana qauly dan lhaqy, manhajiy sebenarnya sudah diperaktekkan Ulama-ulama NU terdahulu, walaupun tidak dengan istilah "manhajiy" ataupun keputusan resmi namun jika dilihat dari kriteria dan 'identitasnya' metode ini sudah lama dipakai. Sebagai contoh, dalam keputusan 
Muktamar 1 thn 1926:22yang menguraikan dapatnya pahala si mayit atas sadaqah yang dikeluarkan keluarga dan atau orang lain yang masih hidup, hal ini disandarkan jawabannya dengan mengutip hadis yang diriwayatkan Imam al-Bukhari:

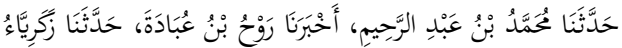

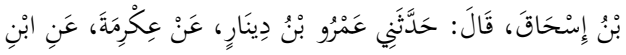

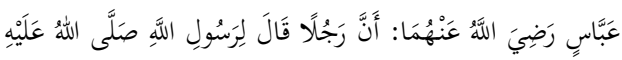

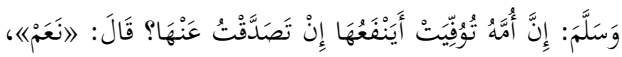

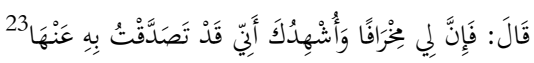

Ibnu Abbas meriwayatkan bahwasanya ada seseorang bertanya kepada Rasulullah Saw, sungguh ibuku telah meninggal, apakah dia memperoleh manfaat apabila saya bersedekah untuknya?? Maka beliau menjawab 'ya' dapat, Dia berkata sungguh saya mempunyai keranjang buah, maka kupersaksikan kepadamu bahwasanya saya telah menyedekahkannya untuk dia.

Keputusan di atas dikategorikan sebagai keputusan yang didasarkan pada metode manhajiy karena langsung merujuk kepada hadits yang merupakan dalil yang dipergunakan oleh keempat Imam mazhab setelah al-Qur'an. Dengan

\footnotetext{
22Martin Bruinessen, NU Tradisi, Relasi-relasi Kuasa Pencarian Wacana Baru, hlm.14

${ }_{23}$ Muhammad bin Ismail Abu Abdillah alBukhari al-Ja'fiya, Lijami' al-Sahih al-Mukhtasar Sahih alBukhari), Juz IV, Bab idzaWuqifaArdlanWalam Yubayyin alHudud, No : 2770, (Cet: III, Da>r IbnKasir, al-Yamamah, Beirut), hal.11. Dan selanjutnya disebut al-Bukhari.
}

melihat metode penyelesaian masalah dalam Lajnah Bahtsul Masa'il diatas dapat disimpulkan dalam meyelesaikan persoalan ummat, NU dapat dikatakan tidak 'enggan' memakai hadis, kendati memakai suatu hadis namun Nahdiyyin tidak serta merta langsung merujuk kepada teks hadis melainkankan memahaminya dengan mereferens kembali kepada pemahaman Imam yang empat terhadap hadis tersebut (kitab al-Mu'tabarah).

Adapun Kriteria pemakain Hadis dalam Bahtsul Masa'il dan penerimaan nya atas Hadis Dhaif. Dengan melihat metode dalam Lajnah Bahtsul Masa'il diatas, terlihat bahwa NU dalam menggunakan hadis Nabi Saw tidaklah memilki krieteria tertentu tentang hadis yang dijadikan sebagai hujjah ataupun tidak. namun yang jelas 'berbeda' dengan organisasi pembaharu semisal Muhammadiyah dan yang lainnya dengan jargon 'Back to Qur'an dan Hadis' tentunya akan memilki kriteria-kriteria hadis tersendiri dalam penetapan hadis yang bisa dijadikan hujjah dan atau tidak

Kemudian, lebih dari itu leiteratur yang membahas secara spesifik mengenai hadis-hadis yang bisa diterima dalam NU secara umumnya, masih sangat terbatas 
namun secara umum, dalam amaliyah dan istinbath-nya NU masih mentolerer hadis yang berstatus dhaif meskipun dengan adanya beberapa persyaratan, dengan catatan hadis ini dipakaki 'hanya' dalam lingkup Fadha'il Amal. Kendati demikian, hadis dhaif juga kerap diterima dalam Lajnah Batsul Masa'il. Perdebatan dalam lingkup pemakaian hadis dhaif sebagai hujjah baik dibidang hukum atau aqidah sangatlah beragam dikalangan ulama' muhaddisin maupun fuqaha', secara umum terbagi menjadi tiga kategori yakni:

1. menerima hadis dhaif secara muthlak, baik mengenai fadhail maupun ahkam, diantara ulama yang memakai pendapat ini adalah Ibnu 'Arabiy, al-Bukhari dan Imam Muslim serta Ibn Hazm.

2. Hadis dhaif bisa diamalkan secara muthlak pendapat ini dinisbatkan kepada Abu Daud dan Imam Ahmad, keduanya berpendapat bahwa hadis dhaif lebih kuat dari $r a^{\prime} y u$ Sebagaimana yang direkomendasikan Imam Ahmad ضعيف المديث اقوى من : denganungkapannya الرائي

3. Hadis dhaif bisa digunakan dalam masalah fadhail amal, mawa'idz atau

\footnotetext{
24 Hasyim Abbas Hasyim Abbas, Kritik Matan Hadis Versi Muhaddisin dan Fuqaha, (Cet; I Yogyakarta:Teras.2004), h. 64
}

yang sejenis bila memenuhi syarat. ${ }^{25}$

Sebagaimana halnya diatas, ketika NU menerima keberadaan hadis dhaif Ia berpandangan bahwa selemah-lemahnya hadis dhaif masih baik dibandingkan dengan $r a^{\prime} y u$, dalam pada itu Ijma' ulama juga telah membolehkan pemakaiannya dalam lingkup fadha'il amal, hal ini disandarkan pada ungkapan Imam Nawawi, dalam beberapa karyanya menyatakan "telah ijma ulama atas diperbolehkannya penggunaan hadits dhaif (ringan) untuk fadhoil amal".

Sebagai contoh, Imam Nawawi dan Al hafidz Ibnu Hajar dalam menyusun kitab yang diberi nama 'Arbain' (kumpulan 40 hadis) ini didasarkan atas 'mengamalkan' hadits Rasulullah Saw: Artinya Barang siapa diantara umatku yang hafal 40 hadits tentang urusan agamanya, maka Allah akan membangkitkannya di hari kiamat nanti dalam kelompok ahli fiqh dan ulama". Mayoritas Ulama hadis mengomentari validitas hadis di atas sepakat atas kedhaifan hadits tersebut, namun tidak dipungkiri hadis inilah yang

25 Ada beberapa syarat tawaran Ibnu Hajar ketika mentolerer atau melaksanakan suatu hadis yang dhaif, diantaranya: tingkat kedhaifannya tidak terlalu berat, hadisnya masuk dalam cakupan amaliyah dan targhib wa tarhib, ketika mengamalkannya tidak meyakini bahwa ia berstatus kuat hanya sekedar berhati hati. Muhammad Ajjaj al-Khatib, Ushul al-Hadis terj Qodirun Nur dan Ahmad Musyafiq, (Cet; IV, Jakarta: Gaya Media Pratama. 2007), h. 314. 
menjadi dasar mereka menyusun kitab "Arbain" yang dengannya umat Islam bisa mengakses hadis-hadis Rasulullah dan mengetahui hukum di dalamnya. ${ }^{26}$

Munawwir Abdul Fattah dalam bukunya Tradisi Orang-orang NU memberikan penjelasan bahwa ada beberapa prosedur sistem pengambilan keputusan dalam ruang lingkup NU yakni27:

1. Dalam kasus ketika jawaban bisa dicukupi oleh ibarat kitab (tekstual), dan disana terdapat hanya satu qaul/wajh28,maka dipakailah qaul/ wajh sebagaiman yang diterangkan teks tersebut.

2. Dalam kasus ketika jawaban bisa dicukup ibarah kitab, dan disana terdapat dari lebih satu qaul/wajh, maka dilakukan taqrir jam" ${ }^{29}$ demi memilih satu qaul/wajh.

3. Dalam kasus dimana tidak ada satu qaul/ wajh yang memberikan penyelesaian, maka yang dilakukan ialah ilhaq al-Masail bi nazhairiha (menganalogikan kasus) secara jama"i (kolektif) oleh para

26http:/ / forum.nu.or.id/viewtopic.php? $\mathrm{f}=5 \& \mathrm{t}=6$ 26 diakses tanggal 25 November 2019.

${ }^{27}$ Munawwir Abdul Fattah, Tradisi Orang-orang NU, (Cet; IX, Yogyakarta, PT. LKIS Printing Cemerlang, 2012), h. 31

${ }^{28}$ Qaul dalam hal ini pendapat imam mazhab, sedangkan wajh ialah pendapat Ulama mazhab.

${ }^{29}$ Taqrir Jam"i iyalah Upaya kolektif untuk menetapkan pilihan. ahlinya, dalam kata lain dilakukan qiyas.

4. Dalam kasus tidak ada satu qaul/ wajh sama sekali dan tidak mungkin dilakukan ilhaq (metode menyamakan), maka bisa dilakukan istimbat jama" $i$ (pengambilan keputusan secara kolektif) dengan prosedur bermazhab secara manhajijo, oleh para ahli, dalam kata lain dilakukan ijmak.

\section{Kesimpulan}

Nahdlatul dalam mengambil sumber hukum Islam melelui beberapa tahap diantaranya, PertamaNU dalam mengambil sumber ajaran islam menempatkan al-Qur'an sebagai sumber pedoman yang utama kemudian alSunnah sebagai sumber hukum islam yang kedua. Nahdlatul Ulama berkeyakinan teguh tidak akan berubah sedikitpun bahwa Islam sebagai agama Allah Swt yang bersumber kepada wahyunya yang telah berwujud kitab alQur'an dan al-Hadis sebagai sumber hakiki. Dalam al-Qur'an dan hadis, sumber hukum sebagai sumber utama hukum Islam bagi NU tidak ada pilihan lain kecuali menerima dan mengikuti

${ }^{30}$ Manhaji dalam hal ini di artikan ialah mengikuti jalan pikiran dan kaedah penetapan yang telah disusun oleh para Imam. 
hukum yang sudah jelas dan pasti tersebut.

Kedua, dengan melihat metode dalam Lajnah Bahtsul Masa'il diatas, terlihat bahwa NU dalam menggunakan hadis Nabi Saw tidaklah memilki krieteria tertentu tentang hadis yang dijadikan sebagai hujjah ataupun tidak. namun yang jelas 'berbeda' dengan organisasi pembaharu semisal Muhammadiyah dan yang lainnya dengan jargon 'Back to Qur'an dan Hadis' tentunya akan memilki kriteria-kriteria hadis tersendiri dalam penetapan hadis yang bisa dijadikan hujjah dan atau tidak. Sehingga dalam mengistinbatkan sumber hukum Islam dapat terjadi perbedaan.

Ketiga, Nahdlatul Ulama dalam mengistinbatkan suatu hukum tetap merujuk kepada kitab-kitab klasik. Jika suatu hukum tidak ditemukan dalama kitab-kitab para ulama terdahulu maka $\mathrm{Nu}$ menggunakan ijtihad dan disesuaikan dengan keadaan masyarakat.

\section{Referensi}

1. Abbas, Hasyim, Kritik Matan Hadis Versi Muhaddisin dan Fuqaha, Cet; I Yogyakarta:Teras.2004.

2. Abdalla, Ulil Abshar, "NU dan Generasi Baru" Dalam Dinamika Kaum Muda" ,jakarta: PP-IPNU, 1997.

3. al-Allah, al-Qazwani, Muhammad ibn Yazid Abu 'Abd, Sunan Ibnu Majah. Juz II. Bairut: Maktab al-Ma'arif Linats \irwa al-Tauzi'. 1417 H.
4. Alauddin, Mughalatai bin Qalijin bin Abdullah al-Bukjari al-Misri al-Hakri al-Hanafi Abu Abdullah, Ikmalu Tahzib al-Kamal fi al-Asmai al-Rijal, juz III, alFaruq al-Hadisi li al-Tabaati wa alNasyri $1422 \mathrm{H}$

5. al-Bai'i, Abu' Abdullah al-Hakim Muhammad bin 'Abdullah bin Muhammad bin Hamdawiyyah bin $\mathrm{Nu}^{\prime}$ im bin al-Hakim al-Dhabi alTahamani al-Naisaburi, Mustadrak ala al-Shahihain,juz I, Bairut: Dar al-Kutubi al-'Alamiyyah $1411 \mathrm{H}$.

6. al-Ja'fiya, Muhammad bin Ismail Abu Abdillah al-Bukhari, Lijami' al-Shahih al-Mukhtasar (Sahih al-Bukhari), Juz IV, Bab idza Wuqifa Ardlan Walam Yubayyin al-Hudud, No : 2770, Cet: III, Dar Ibn Kasir, al-Yamamah, Beirut.

7. al-Khatib, Muhammad Ajjaj, Ushul alHadis terj Qodirun Nur dan Ahmad Musyafiq, Cet; IV, Jakarta: Gaya Media Pratama. 2007.

8. Amin, M. Masyhur, NU EIjtihad Politik Kenegaraannya,Cet; I, Yogyakarta: alAmin, 1996.

9. Asy'ari, K.H.M Hasyim, Sang Kiyai Fatwa, K.H.M Hasyim Asy'ari Seputar Islam dan Masyarakat, Terj: Jamal Ma'ruf Asmani.

10. Bruinessen, Martin, NU Tradisi, Relasirelasi Kuasa Pencarian Wacana Baru,Cet; I, Yogyakarta: LKIS. 1994.

11. Dhofier, Zamakhsyari, Tradisi Pesantren, Studi Tentang Pandangan Hidup Kiyai, Jakarta: LP3ES. 1984.

12. Fattah, Munawwir Abdul, Tradisi Orang-orang NU, Cet; III, Yogyakarta: PustakaPesantren LKIS 2012.

13. Bruinessen Martin, NU Tradisi, Relasirelasi Kuasa Pencarian Wacana Baru, Yogyakarta: LKIS. 1994.

14. Said Ghazali Imam, Edisi Revisi Solusi Hukum Islam, Keputusan Muktamar, Munas, dan Konbes Nahdlatul Ulama (1926-2004), Surabaya: Diantama,2006. 
15. Tim Aswaja NU Center PWNU Jawa Timur, Khazanah Aswaja, "Memahamai, Mengamalkan dan Mendakwahkan Ahlussunah wal Jama'ah" Jawa Timur: Tim Aswaja NU Center PWNU, 2016. 